\title{
Iatrogenic vitamin D overdose resulting in acute pancreatitis with acute kidney injury
}

\author{
Rajesh Singh ${ }^{1}$, Manish R Balwani ${ }^{2}$, Umesh Godhani ${ }^{3}$, Pravin Ghule ${ }^{4}$, Priyanka Tolani ${ }^{5}$, Vivek Kute ${ }^{6}$
}

\begin{abstract}
Vitamin D deficiency is prevalent worldwide. Most of patients with mild vitamin D deficiency are often over-treated with higher dose of vitamin D supplementation than required resulting in toxic levels of vitamin D. While correcting, one should regularly look for adverse effects of overcorrection resulting in hypervitaminosis D. We discuss here a similar case of 34-year-old woman who presented to us with persistent acute abdominal pain since 48 hours and oliguria since 24 hours. She was found to have hypercalcemia induced pancreatitis with acute kidney injury. Cause of hypercalcemia was found to be hypervitaminosis D. Thereafter, she was treated with aggressive hydration and diuretics, and required calcitonin for control of hypercalcemia to which she responded. Thus we suggest that in any patient who presents with hypercalcemia with low parathyroid levels, hypervitaminosis D should be suspected. Primary care physicians should be alerted of such cases, to avoid overcorrection of vitamin D. Mild vitamin D deficiency should be initially corrected with adequate sunlight exposure and fortified/enriched vitamin D food supplements.

Keywords: Hypercalcemia, Hypervitaminosis D, Acute kidney injury, Acute pancreatitis

Please cite this paper as: Singh R, Balwani MR, Godhani U, Ghule P, Tolani P, Kute V. Iatrogenic vitamin D overdose resulting in acute pancreatitis with acute kidney injury. J Parathyr Dis. 2018;6(1):29-31. DOI: 10.15171/jpd.2018.10.

Copyright (๑) 2018 The Author(s); Published by Nickan Research Institute. This is an open-access article distributed under the terms of the Creative Commons Attribution License, which permits unrestricted use, distribution, and reproduction in any medium, provided the original work is properly cited.
\end{abstract}

\section{Introduction}

Vitamin D role is crucial in maintenance of bone mineral metabolism and calcium homeostasis. Vitamin D deficiency results in a mineralization defect in the adult skeleton causing osteomalacia. The US National Academy of Science has recommended daily allowance of vitamin $\mathrm{D}$ as 600 units/day for persons under seventy years of age, and for persons older than 70 years as 800 units/day. Mild vitamin D deficiency can be corrected with timely adequate sun exposure and vitamin D fortified foods. Whereas moderate to severe vitamin $\mathrm{D}$ deficiency needs pharmacological correction with supplementation of vitamin D $50000 \mathrm{IU} /$ week for 6 to 8 weeks (1). In recent years, many cases of hypervitaminosis $\mathrm{D}$ are reported due to iatrogenic overcorrection of mild vitamin D deficiency. We here discuss a similar case of iatrogenic hypervitaminosis $\mathrm{D}$, which leads to hypercalcemia induced acute pancreatitis with acute kidney injury.

\section{Case Presentation}

A 34-year-old Indian female came to our hospital with complains of abdominal pain, vomiting, and decreased appetite since 48 hours and oliguria since 24 hours. There was no history of hematuria, hesitancy of urination, pedal edema, joint pain, fever, decreased sensorium, headache, cough or shortness of breath. On clinical examination, the patient was afebrile, well oriented to time, place and person. Pallor, icterus and edema feet were absent. Blood pressure was $132 / 82 \mathrm{~mm} \mathrm{Hg}$ with pulse and respiratory rate of $86 /$ minute and $22 /$ minute respectively. An abdominal examination revealed guarding and rigidity in right lumbar and periumbilical region. Cardiovascular, respiratory and central nervous system examinations revealed no major significant findings. Laboratory investigations showed following results; hemoglobin was $10.2 \mathrm{~g} / \mathrm{dL}$, total leucocyte count was $13.4 \times 10^{3} / \mathrm{mm}^{3}$, platelet count was $262 \times 10^{3} / \mathrm{mL}$. Additionally, blood urea nitrogen (BUN); $69 \mathrm{mg} / \mathrm{dL}$, serum creatinine; $4.26 \mathrm{mg} / \mathrm{dL}$, serum bilirubin; $0.80 \mathrm{mg} / \mathrm{dL}$, protein; $6.9 \mathrm{~g} / \mathrm{dL}$, albumin; $3.9 \mathrm{~g} / \mathrm{dL}$, globulin; $3.0 \mathrm{~g} / \mathrm{dL}$, alanine transaminase; $18 \mathrm{IU} / \mathrm{L}$, aspartate transaminase; $20 \mathrm{IU} / \mathrm{L}$, alkaline phosphatase; 22 IU/L, sodium; $136 \mathrm{mEq} / \mathrm{L}$, potassium; $2.95 \mathrm{mEq} / \mathrm{L}$, serum calcium; $16.8 \mathrm{mEq} / \mathrm{L}$, phosphorous; $6.4 \mathrm{mEq} / \mathrm{L}$, and erythrocyte sedimentation rate was $48 \mathrm{~mm}$ at the end of 1 hour. Her urine analysis and microscopy were normal except for albuminuria of $30 \mathrm{mg} / \mathrm{dL}$. Serum amylase and lipase were 1319 and $3044 \mathrm{IU} / \mathrm{mL}$ respectively. Her chest X-ray and electrocardiogram were normal. An ultrasound examination of abdomen revealed bulky pancreas. Magnetic resonance imaging (MRI) abdomen 
Implication for health policy/practice/research/ medical education

When a patient presents with hypercalcemia predominantly in the presence of normal or low parathyroid hormone, then a diagnosis of overzealous correction of vitamin D should be suspected. Its early diagnosis will not only improve symptoms but will also prevent ongoing acute renal damage. Primary treating physicians should be aware of iatrogenic hypervitaminosis D. Mild vitamin D deficiency should be corrected with adequate sunlight exposure and fortified/ enriched vitamin D food supplements.

was suggestive of bulky pancreas mainly body and tail with peri-pancreatic inflammatory changes suggestive of acute pancreatitis with no signs of necrosis. Serum 25 $(\mathrm{OH})$ vitamin D level was high $(>120 \mathrm{ng} / \mathrm{mL})$. Parathyroid hormone level was low $(12.20 \mathrm{pg} / \mathrm{mL})$. To summarize, the patient had raised BUN and serum creatinine, high amylase/lipase levels, raised serum calcium and $25 \mathrm{OH}$ vitamin D levels with low serum parathyroid hormone suggesting acute pancreatitis with acute kidney injury due to hypercalcemia. Hypervitaminosis D was thought to be the cause of hypercalcemia. For hypercalcemia, the patient was hydrated and treated with intravenous fluid, loops diuretics and nasal calcitonin spray to which she gradually responded in 14 days. She was discharged with normal kidney function tests with serum calcium level of $8.6 \mathrm{mg} / \mathrm{dL}$. Her previous detailed history revealed that, the patient had consulted primary physician for complaint of perioral numbness around one month back. She was first evaluated at that time and found to have hypocalcemia (serum calcium; $8.2 \mathrm{mg} / \mathrm{dL}$ ) with low vitamin D levels (serum $25 \mathrm{OH}$ vitamin $\mathrm{D} ; 16 \mathrm{ng} / \mathrm{mL}$ ). Thereafter, she was treated with an intravenous injection of calcitriol $0.5 \mathrm{mg}$ once 21 days back followed by weekly supplementation of oral cholecalciferol 60000 IU along with oral calcium carbonate $1000 \mathrm{mg} / \mathrm{d}$. Thus a diagnosis of iatrogenic hypervitaminosis D induced hypercalcemia was made leading to acute pancreatitis with acute kidney injury.

\section{Discussion}

Hypervitaminosis D can manifest as hypercalcemia induced organ dysfunction like acute kidney injury as in this case (2). 1, 25-dihydroxyvitamin D3 is the biologically active metabolite of vitamin $\mathrm{D}$ and it is central to bone mineral homeostasis. It has many diverse physiologic functions including protection against various immune related disorders (3). Adequate vitamin D status has been linked to decreased risks of developing specific cancers, like malignancies of the esophagus, skin, thyroid, stomach, lung, breast, uterus, ovary, prostate, colon, rectum, gallbladder, pancreas, urinary bladder, kidney and hematopoietic system (for example, multiple myeloma Hodgkin's lymphoma and non-Hodgkin's lymphoma). Vitamin D sufficient levels have also been found to be associated with decreased risk of bacterial infections, multiple sclerosis, Crohn's disease, hypertension, type
2 diabetes, rheumatoid arthritis, stroke, cardiovascular disease, peripheral vascular disease and chronic kidney disease (4).

The body produces vitamin D only after adequate sunlight exposure. When regular sunlight exposure is less, foods are not enough to maintain appropriate levels of vitamin $\mathrm{D}$ in the body. Hence supplementation or fortification of foods with vitamin D is necessary. The recommended dose on daily basis varies from 800 to 4000 IU according to the age $(5,6)$.

Mild vitamin D deficiency is usually treated with adequate sun exposure. Moderate vitamin D deficiency requires pharmacological doses of vitamin D supplementation for its treatment. Recommended pharmacological dose of vitamin D is $50000 \mathrm{IU} /$ week for 6 to 8 weeks (1). Due to wide therapeutic index, vitamin D toxicity is not common. The US Food and Nutrition Board remarks that healthy adults can consume daily vitamin D maximum up to 2000 IU without any major risk of hypercalcemia (7). During correction, such individuals should be checked by periodic regular 24-hour urinary calcium excretion estimation, which should be less than $250 \mathrm{mg} / \mathrm{d}$.

Hypervitaminosis D clinically manifests as nausea, vomiting, anorexia, constipation, polyuria, headache, hypertension, hypercalcemia, hyperphosphatemia, hypercalciuria and kidney stones $(8,9)$.

Koul et al (10) presented case series of 15 patients with iatrogenic symptomatic hypercalcemia. They found, toxicity occurred mainly due to empirical excessive administration of vitamin D either by oral and parenteral route. Authors in this report concluded that healthcare providers should be made increasingly aware of toxic potential of overcorrection of vitamin $\mathrm{D}$ resulting in iatrogenic hypervitaminosis $\mathrm{D}$, despite its wide therapeutic index (10).

In our case, the patient had mild vitamin $\mathrm{D}$ deficiency. She was treated aggressively with pharmacological doses of vitamin D supplementation along with an active form of vitamin D as intravenous calcitriol. She developed hypervitaminosis $\mathrm{D}$ induced hypercalcemia which consequently lead to acute pancreatitis and acute kidney injury. Such mild vitamin D deficiency in our view should be treated with adequate and proper timed sun exposure and vitamin $\mathrm{D}$ fortified healthy foods. Intravenous calcitriol should be reserved only for indicated cases where active form of vitamin D is needed like chronic kidney disease, secondary hyperparathyroidism and pseudohypoparathyroidism.

\section{Conclusion}

Over-dosage of vitamin D should be suspected whenever patient presents with hypercalcemia with low parathyroid hormone levels. Detailed previous medical history should be sought especially in such cases to look for vitamin D and calcium supplementation. Primary treating physicians should be aware of increasing prevalence of iatrogenic hypervitaminosis D. Mild vitamin D deficiency should be initially corrected with adequate sunlight exposure and 
fortified/enriched vitamin D food supplements rather than aggressive pharmacological correction.

Authors' contribution

All authors contributed equally to the study.

\section{Conflicts of interest}

The authors report no conflicts of interest. The authors alone are responsible for the content and writing of the article.

\section{Ethical considerations}

Ethical issues (including plagiarism, data fabrication, double publication) have been completely observed by the authors. The authors obtained informed consent from the patient.

\section{Funding/Support}

None.

\section{References}

1. Robert MR, Paolo MS. Vitamin and trace mineral deficiency and excess. In: Longo DL, Fauci AS, Kasper DL, Hauser SL, Jameson JL, Loscalzo J, eds. Harrison's Principles of Internal Medicine. Volume 1. 18th ed. New York: Mc Graw Hill; 2012:594-605.

2. Hathcoch JN, Glao A, Vieth R, Haeny R. Risk assessment for vitamin D. Am J Clin Nutr. 2007;85:6-18.

3. Christakos S, Ajibade DV, Dhawan P, Fechner AJ, Mady LJ. Vitamin D: metabolism. Endocrinol Metab Clin North Am. 2010;39:243-53.

4. Glade MJ. Vitamin D: health panacea or false prophet? Nutrition. 2013;29:37-41.

5. Holick MF. Vitamin D deficiency. $N$ Engl J Med. 2007;357:266-81.

6. Holick MF, Binkley NC, Bischoff-Ferrari HA, Gordon CM, Hanley DA, Heaney RP, et al. Evaluation, treatment, and prevention of vitamin D deficiency: an Endocrine Society clinical practice guideline. J Clin Endocrinol Metab. 2011;96:1911-30.

7. John TP Jr, Harald J. Disorders of the parathyroid gland and calcium homeostasis. In: Longo DL, Fauci AS, Kasper DL, Hauser SL, Jameson JL, Loscalzo J, eds. Harrison's Principles of Internal Medicine. Volume 2. 18th ed. New York: Mc Graw Hill; 2012:3096-3120.

8. Bouillon R. Vitamin D: from photosynthesis, metabolism, and action to clinical application. In: DeGroot LJ, Jameson JL, eds. Endocrinology. 6th ed. Philadelphia: WB Saunders; 2010:1089-1110.

9. Maji D. Vitamin D toxicity. Indian J Endocrinol Metab. 2012;16:295-6.

10. Koul PA, Ahmad SH, Ahmad F, Jan RA, Shah SU, Khan UH. Vitamin d toxicity in adults: a case series from an area with endemic hypovitaminosis D. Oman Med J. 2011;26:201204. 